\title{
A crise de identidade dos cursos de Sistemas de Informação é percebida "além-muros" das universidades no sul do Brasil?
}

\section{Title: Is the identity crisis of Information Systems courses perceived "beyond walls" of universities in southern Brazil?}

\author{
Rita Cristina Galarraga Berardi, Silvia Amelia Bim
}

Academic Department of Informatic- Federal University of Technology of Paraná (UTFPR)

\author{
Curitiba, Paraná - Brazil \\ \{ritaberardi, sabim\}@utfpr.edu.br
}

\begin{abstract}
One of the concerns that surround both research and academic formation at Information Systems (IS) courses in Brazil is the identity that IS courses seek to achieve. It is well known that there is a crisis inherent in this identity due to the foundations of the area which were built by two divergent communities: on the one hand Computer Science - with its algorithmic objectivity and technological solutions - on the other hand, Business School, with its subjectivity and systemic reflection on the contexts in which the technological solutions are inserted. The objective of this work is to identify if this crisis is perceived by the students before entering the course or only after, besides verifying how this perception is constructed. The methodological procedures included quantitative and qualitative methods for statistical and empirical descriptive analysis of data collected from students of IS courses, as well as documentary study on the sites of IS courses. As a result, through 133 students from 4 courses in the southern region of Brazil, it was possible to detect that the crisis can occur "beyond walls", since a good portion of students creates a false expectation about the course, waiting for its approach exclusively in programming.
\end{abstract}

Keywords. Identity crisis; Information System; Beyond walls; Southern Brazil.

Resumo. Uma das preocupações que envolvem tanto a pesquisa quanto a formação acadêmica brasileira em Sistemas de Informação (SI) diz respeito à identidade que os cursos de SI buscam alcançar. É sabido que há uma crise inerente a essa identidade devido às fundações da área terem sido construídas por duas comunidades divergentes e complementares entre si: de um lado a Computação - com sua objetividade algorítmica e soluções tecnológicas - de outro, a Administração, com sua subjetividade e reflexão sistêmica sobre os contextos em que as soluções tecnológicas estão inseridas. O objetivo deste trabalho é identificar se essa crise é percebida pelos estudantes antes de ingressar no curso ou somente depois, além de verificar como essa percepção é construída. Os procedimentos metodológicos incluíram métodos

Cite as: Berardi, R. C. G. \& Bim, S. A. (2017). A crise de identidade dos cursos de Sistemas de Informação é percebida "além-muros" das universidades no sul do Brasil? (Is the identity crisis of Information Systems courses perceived "beyond walls" of universities in southern Brazil?). iSys: Revista Brasileira de Sistemas de Informação (Brazilian Journal of Information Systems), 10(4), 24-44. 
quantitativos e qualitativos para análise descritiva estatística e empírica de dados coletados de estudantes de cursos de SI, bem como estudo documental nos sites dos cursos de SI. Como resultado obtido, por meio de 133 estudantes de 4 cursos da região sul do Brasil, foi possível detectar que a crise pode sim ocorrer "além-muros", visto que uma boa parcela de estudantes cria uma falsa expectativa quanto ao curso, esperando seu enfoque exclusivamente em programação.

Palavras-Chave. Crise de Identidade; Sistemas de Informação; Além-muros; Sul do Brasil

\section{Introdução}

Entender os aspectos atuais e futuros da pesquisa na área de SI implica em compreender como os próprios estudantes percebem a área de SI enquanto uma formação acadêmica ou uma possível área de pesquisa científica. Por muito tempo essa área foi percebida como uma identidade em crise, por apresentar uma fragmentação de comunidades, em que ora seu enfoque acontece nas disciplinas mais técnicas da Computação e ora enfatiza disciplinas mais teóricas da Administração. Isto pode resultar em pesquisas nem tão práticas, por não se caracterizar um trabalho puramente da área de Computação, ou nem tão relevantes, por apresentar um artefato técnico sem a análise do seu contexto organizacional ou social [Rodrigues e Ludmer 2005] [Benbasat e Zmud 1999] [Davenport 1997].

A dificuldade de definições sobre quais disciplinas, com qual aprofundamento e quais competências devem ser desenvolvidas em um curso de SI, ocorre historicamente tanto no cenário nacional como internacional. Nesse sentido, esforços têm sido concentrados para se construir um currículo que revele as características do curso tanto em termos de disciplinas como de competências.

No cenário internacional a Association for Computing Machinery $(\mathrm{ACM})^{1}$ e a Association for Information Systems (AIS) ${ }^{2}$ definem um escopo de conhecimento para a formação nos cursos de Tecnologia da Informação (TI) como Ciência da Computação, Engenharia de Computação e Sistemas de Informação. A recomendação de currículo da ACM (2010) defende uma formação capaz de acontecer em qualquer contexto, sem privilegiar um sistema de educação sobre outro. Esta formação contempla uma visão multidisciplinar de um profissional de SI, abrangendo competências de diferentes áreas que vão desde conhecimentos específicos de tecnologia como Desenvolvimento e Implantação de Sistemas, Infraestrutura de TI, Gestão de dados, de informações e de conteúdo, interseccionados com áreas mais relacionadas à gestão dessas tecnologias em contextos organizacional e social como Empreendedorismo, Inovação e Mudanças Organizacionais, Sistemas de Informação gerenciais e operacionais. Como competências individuais, devem desenvolver, dentre outros, pensamento crítico, solução de problemas, análise ética, comunicação oral, competências matemáticas e estatísticas, trabalho em equipe, liderança, ou seja, delineia um perfil bem diversificado, não focando apenas em competências "técnicas", mas interpessoais também.

No Brasil, a Sociedade Brasileira de Computação (SBC) definiu um Currículo de Referência para os cursos de SI [SBC 2013] e o Ministério de Educação (MEC) o assume como base para os cursos de graduação [MEC 2012]. Além do currículo, as

\footnotetext{
${ }^{1} \mathrm{http}: / /$ www.acm.org/

2 https://aisnet.org/
} 
competências também são indicadas pelo MEC que define, dentre outras: modelar e implementar soluções de TI em variados domínios, gerenciar, manter e garantir segurança de sistemas e infraestrutura de TI, aplicar métodos e técnicas de negociação, gerenciar equipes de trabalho no desenvolvimento de SI e fazer estudos de viabilidade financeira. Ainda como perfil do egresso do curso de SI, o MEC aponta, dentre outras características:

- possuir sólida formação em Ciência da Computação, Matemática e Administração visando o desenvolvimento e a gestão de soluções baseadas em TI para os processos de negócio das organizações de forma que elas atinjam efetivamente seus objetivos estratégicos de negócio;

- entender os modelos e as áreas de negócios, atuando como agentes de mudança no contexto organizacional;

- desenvolver pensamento sistêmico que permita analisar e entender os problemas organizacionais;

- entender o contexto no qual as soluções de sistemas de informação são desenvolvidas e implantadas, atentando para as suas implicações organizacionais e sociais.

Observando a síntese das competências e o perfil do egresso definidos pelo MEC e as definidas pela ACM, é possível verificar que realmente há uma convergência do que seria uma formação em SI, contemplando um caráter aplicado com integração de conhecimentos técnicos, analíticos e interpessoais. Porém, apesar de todas essas definições coerentes entre si, essa identidade ainda é recente e carece de solidificação. Essa solidificação deve ser buscada a todo tempo, pois essa crise de identidade pode trazer consequências sérias em todas as esferas da comunidade de SI, desde acadêmica, no dia-a-dia das salas de aulas nos cursos, na evasão dos estudantes, até a falta de pesquisadores dedicados a contribuir continuamente com a área.

$\mathrm{Na}$ esfera acadêmica, trabalhos têm sido desenvolvidos para discutir questões curriculares como atualidade e capacidade de atrair novos estudantes, não somente no curso de SI, mas nos de computação como um todo [Digiampietri et al. 2016] [Helfert e Duncan 2007] [Oliveira Nunes et al. 2015]. A evasão também tem preocupado a comunidade dos cursos de computação como um todo, pois conforme discutem Amorim (2015), Faquin e Araújo (2017), apenas 31\% dos estudantes de cursos de tecnologia da informação e comunicação concluem seus cursos. Em outubro de 2016, a Universidade de São Paulo (USP), uma das mais conceituadas universidades do país, divulgou que mais de $20 \%$ dos estudantes desistem de seus cursos, sendo uns dos cursos de maior média de evasão, os relacionados ao Instituto de Ciências e Matemática e Computação de São Carlos, chegando a 48\%. ${ }^{3}$ Alguns estudos indicam que são variados os motivos da evasão, passando por base matemática fraca, falta de conhecimento prévio sobre o real objetivo do curso, currículos longos, critérios impróprios de avaliação do desempenho discente, entre outros [Cavalcante e Embiruçu, 2013][Medeiros e Melo 2011]. Dahlberg et al. (2008) utilizam atividades de pesquisa como forma de combater a evasão envolvendo os estudantes em atividades que aumentem o interesse deles pela pós-graduação. Segundo os autores, os primeiros anos de experiência resultaram no aumento de habilidades dos estudantes e no interesse em desenvolver pesquisa científica. Thompson et al. (2014) utilizaram estratégia semelhante de envolver alunos em áreas de pesquisa para diminuir evasão de mulheres nos cursos de computação.

\footnotetext{
${ }^{3}$ http://www.jornaldocampus.usp.br/index.php/2016/10/basic-2/
} 
$\mathrm{Na}$ esfera da pesquisa, Araújo et al. (2015) apresentam um histórico de 10 anos de atuação da comunidade de SI sob a perspectiva do Simpósio Brasileiro de Sistemas de Informação (SBSI), no qual os autores salientam que a característica diversificada e multidisciplinar da área acrescenta um desafio quanto à geração de trabalhos relevantes. Isto porque as pesquisas na área abrangem a aplicação prática da computação combinada a abordagens de pesquisa não usuais dessa área. Exemplos desses conflitos multidisciplinares ocorrem dentro do próprio contexto dos cursos de SI, no qual, por vezes, surge o seguinte cenário: uma pesquisa não é considerada como sendo da área de SI por utilizar métodos qualitativos na análise de aspectos comportamentais com uma aplicação de software - aspectos que a área de TI não costuma valorizar [Macedo e Barbosa 2013]. O contrário também ocorre, quando uma pesquisa também pode não ser considerada da área de SI por ter como um dos resultados um artefato de software como parte de um estudo organizacional.

Diante desse contexto, é possível perceber a urgência de se evidenciar algumas razões para que esses conflitos ocorram na área de SI. Questões semelhantes a essa foram abordadas nos trabalhos supracitados, porém, o diferencial deste trabalho é que o tema é abordado considerando as percepções anteriores e durante o curso de SI por meio da participação dos próprios estudantes. Além disto, os trabalhos encontrados na área não envolvem diferentes cursos de uma região, como é feita com a região sul neste trabalho. A alta demanda por parte dos próprios estudantes, por definições quanto ao enfoque do curso, quanto à profundidade das disciplinas técnicas e teóricas e quanto às reais vantagens de se cursar SI, motivou esta pesquisa.

Este artigo pretende contribuir com essa discussão sobre a crise de identidade por meio de um questionamento direto àqueles que têm o potencial de mostrar as verdadeiras crises que envolvem o curso: os próprios estudantes. Em particular, buscase identificar a percepção que os estudantes têm do curso antes de optar por cursá-lo e qual a percepção depois de ingressar no curso. A hipótese é que a crise pode ser percebida "além dos muros" do curso antes mesmo do estudante optar por cursá-lo, e ao longo do curso ela pode ser reforçada por algumas práticas do próprio corpo docente ou pelo contexto do curso. A partir disso surge o problema da pesquisa que consiste em uma pergunta norteadora: A crise de identidade dos cursos de Sistemas de Informação é percebida "além-muros" ou somente "entre os muros" das universidades da região sul do Brasil? Como perguntas secundárias surgem:

1- Antes de ingressar no curso de SI os estudantes percebem o curso como uma área multifacetada ou fragmentada, gerando assim uma crise "além-muros" da universidade?

2- Como é construída a percepção dos estudantes antes de ingressar no curso?

3- Após o ingresso no curso de SI, os estudantes percebem o curso como uma área multifacetada ou fragmentada, gerando assim uma crise "entre os muros" da universidade?

Para responder às perguntas de pesquisa, foi realizado um survey em 4 cursos de SI localizados na região sul do Brasil, utilizando como instrumento de coleta um questionário online. Para a elaboração das perguntas do questionário foi realizada uma análise documental em 7 websites de cursos reconhecidos de universidades brasileiras, tanto públicas quanto privadas, buscando informações quanto à grade curricular, perfil do egresso, e características gerais do curso. 
O restante deste artigo está organizado da seguinte maneira: a Seção 2 descreve a Metodologia; a Seção 3 apresenta os resultados e as análises das respostas ao questionário subdivididas em 3 subseções: subseção 3.1 que tem como objetivo responder à questão secundária 1 analisando a percepção dos estudantes antes de ingressar no curso, subseção 3.2 que tem como objetivo responder à questão secundária 2 analisando as fontes de informação utilizadas pelos estudantes para construir a percepção anterior ao ingresso no curso e a subseção 3.3 que que tem o objetivo de responder à questão secundária 3 analisando a percepção dos estudantes após o ingresso no curso; Seção 4 apresenta comentários gerais dos estudantes e a análise do que se pode aprender com esses comentários e, por fim, a Seção 5 com as considerações finais e sugestões de trabalhos futuros.

\section{Metodologia}

Tanto a abordagem quantitativa quanto qualitativa foi adotada na metodologia desta pesquisa no que tange à coleta de dados de estudantes de cursos de Sistemas de Informação e a sua devida análise descritiva estatística e empírica.

Para investigar a percepção dos estudantes do curso de Bacharelado em Sistemas de Informação (BSI) foi enviado um e-mail para 6 coordenadores de cursos de BSI das regiões sul, sudeste e centro-oeste do Brasil com um pedido de convite aos seus alunos a participar da pesquisa através de um questionário disponibilizado de forma online. A escolha por esses 6 coordenadores foi feita pelo reconhecimento dos seus cursos como os melhores do país.

O questionário possuía 15 perguntas, 13 de múltiplas escolhas e 2 abertas, organizadas em quatro seções: a primeira seção possuía o conjunto de perguntas para identificar o perfil do estudante; a segunda seção foi composta por perguntas para detectar qual a percepção do estudante antes de ingressar ao curso de BSI e como esta foi construída; a terceira seção visava identificar a percepção do estudante durante o curso e se havia contraste positivo ou negativo com a percepção anterior, e a quarta e última seção buscava identificar os planos de carreira após a conclusão do curso.

No total, 133 estudantes de 4 cursos da região sul do Brasil - 2 cursos de universidades privadas e 2 cursos de universidades públicas, responderam ao questionário durante o mês de junho de 2017. A identidade dos cursos em que os estudantes participaram da pesquisa é preservada nesta pesquisa, chamando de BSI1, BSI2 os cursos das universidades públicas e BSI3 e BSI4 os cursos das universidades privadas.

Do total de respondentes, $61.1 \%$ cursam o BSI1, 26\% cursam o BSI2, 9.9\% cursam o BSI3 e $3.1 \%$ cursam o BSI4. Com relação ao semestre que estava cursando no momento da pesquisa, $20.6 \%$ cursavam o $8^{\circ}$ semestre, $15.3 \%$ cursavam o $3^{\circ}$ semestre, $13 \%$ cursavam o $4^{\circ}, 11.5 \%$ cursavam o $1^{\circ}, 10.7 \%$ cursavam o $6^{\circ}, 8.4 \%$ cursavam o $2^{\circ}$, $7.6 \%$ cursavam o $9^{\circ}, 6.9 \%$ cursavam o $5^{\circ}$ e $6.1 \%$ cursam o $7^{\circ}$ semestre. Quanto à faixa etária, $29.8 \%$ possuíam de 21 a 23 anos, $28.2 \%$ possuíam de 17 a 20 anos, $21.4 \%$ possuíam de 24 a 26 anos e $20.6 \%$ possuíam mais de 26 anos. Quanto ao gênero, $80.9 \%$ dos respondentes identificavam-se com o gênero masculino, $18.3 \%$ com o gênero feminino e $0.8 \%$ com outro gênero (não especificado na pesquisa). As quantidades referentes a esta caracterização por curso constam na Tabela 1: 
Tabela 1. Caracterização da amostra dos estudantes participantes

\begin{tabular}{|c|c|c|c|c|c|c|c|c|c|c|}
\hline Curso & Idade Semestre & $1^{o}$ & $2^{o}$ & $3^{o}$ & $4^{\circ}$ & $5^{\circ}$ & $6^{\mathrm{o}}$ & $7^{\circ}$ & $8^{\circ}$ & $9^{\circ}$ \\
\hline \multirow{4}{*}{$\begin{array}{c}\text { BSI1 } \\
(80)\end{array}$} & 17 a 20 & 7 & 5 & 6 & 4 & 1 & 1 & & & \\
\hline & 21 a 23 & 1 & & 3 & 7 & 2 & 3 & 1 & 7 & \\
\hline & 24 a 26 & 1 & 2 & 1 & & & 1 & 2 & 10 & 2 \\
\hline & mais de 26 & & & 4 & 2 & & 4 & & 2 & 1 \\
\hline \multirow{4}{*}{$\begin{array}{c}\text { BSI2 } \\
(34)\end{array}$} & 17 a 20 & 4 & 3 & 1 & 1 & & & & & \\
\hline & 21 a 23 & & & & 2 & & 1 & 1 & & 2 \\
\hline & 24 a 26 & & 1 & & 1 & 2 & 1 & 1 & & 2 \\
\hline & mais de 26 & 1 & & 1 & & 1 & 3 & 2 & 1 & 2 \\
\hline \multirow{4}{*}{$\begin{array}{c}\text { BSI3 } \\
(13)\end{array}$} & 17 a 20 & & & 2 & & 2 & & & & \\
\hline & 21 a 23 & 1 & & 1 & & 1 & & 1 & 2 & \\
\hline & 24 a 26 & & & & & & & & 1 & \\
\hline & mais de 26 & & & 1 & & & & & 1 & \\
\hline \multirow{4}{*}{$\begin{array}{c}\text { BSI4 } \\
(4)\end{array}$} & 17 a 20 & & & & & & & & & \\
\hline & 21 a 23 & & & & & & & & 3 & \\
\hline & 24 a 26 & & & & & & & & & \\
\hline & mais de 26 & & & & & & & & & 1 \\
\hline
\end{tabular}

\section{Resultados e Discussões}

Os resultados obtidos são análises empíricas das respostas ao questionário. Visando responder à pergunta de pesquisa norteadora, são feitas análises para responder às perguntas secundárias com estatística descritiva das respostas buscando analisar qualitativamente os números.

\subsection{Há crise de identidade "além dos muros" dos cursos de SI?}

A primeira pergunta secundária é: Antes de ingressar no curso de SI os estudantes percebem o curso como uma área multifacetada ou fragmentada, gerando assim uma crise "além-muros" da universidade? Para responder esta pergunta são analisadas as respostas das seguintes perguntas do questionário: "Por que você decidiu cursar Bacharelado em Sistemas de Informação?" e a pergunta "Antes de entrar no curso de BSI com o que você planejava trabalhar após formado(a)?". Estas perguntas mostram qual a percepção que estudantes externos à comunidade podem ter com relação ao curso e com relação às oportunidades que ele pode oferecer à vida profissional no futuro. 


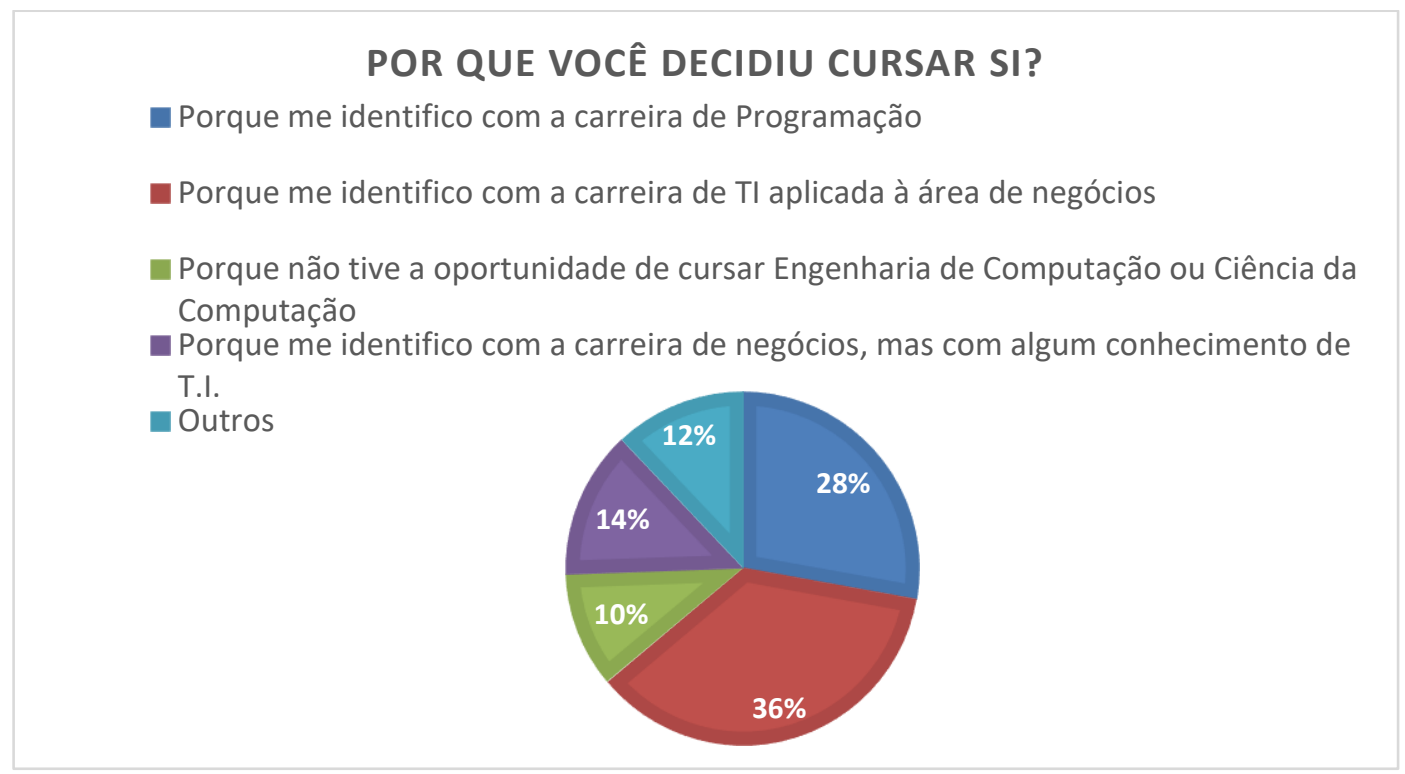

Figura 1. Respostas à pergunta "Por que decidiu cursar SI?"

No gráfico da Figura 1 é possível observar que a maior parte das respostas (36\% - 48 respostas) identificaram o perfil do curso relacionado a uma carreira de TI aplicada à área de negócios. Dentre as possíveis respostas, esta reflete uma percepção multifacetada e não fragmentada. Porém, é interessante notar, que a segunda resposta mais escolhida foi a que liga o curso a uma visão fragmentada, puramente de programação, com 28\% (37 respostas) das respostas. Esta resposta mostra que havia, por alguns estudantes, uma falsa expectativa de que o curso é totalmente focado à área de programação. Esta impressão de que o curso possui um foco fragmentado é confirmada pelos números apresentados no gráfico da Figura 2 que mostra as respostas à pergunta "Antes de entrar no curso de BSI com o que você planejava trabalhar após formado(a)?". A esta pergunta, a maioria respondeu que "Pensava em trabalhar com Programação" com 28\% - 37 respostas.



Figura 2: Respostas à pergunta "Antes de entrar no curso de BSI com o que você planejava trabalhar após formado (a)?"

Essa expectativa reflete uma pequena "crise de identidade" externa ao contexto do curso. As consequências podem ser diversas, como desmotivação de alguns estudantes quando se deparam com disciplinas obrigatórias com foco mais teórico como gestão, administração, entre outras ou até mesmo chegando à evasão. 
Esse tipo de análise pode ajudar a responder algumas inquietações, pois muitas vezes docentes e coordenadores buscam razões somente dentro do contexto do próprio curso para o baixo desempenho dos estudantes em algumas disciplinas ou até para a evasão. Entretanto, através dessa análise, é possível também passar a considerar o que ocorre na comunidade externa, principalmente com a formação da visão que os possíveis estudantes podem ter do curso.

Com essas duas perguntas seria possível responder que uma parcela considerável de estudantes, antes de ingressar no curso de SI, percebe o curso como uma área fragmentada, o que pode gerar algum tipo de crise já "além-muros" da universidade. Porém, há de se destacar positivamente que a maioria tem uma visão mais próxima da esperada, como uma área multifacetada.

\subsection{Como a percepção dos estudantes é construída "além-muros" dos cursos de SI?}

A segunda pergunta secundária é: Como a percepção dos estudantes antes de ingressar no curso é construída? Para responder esta pergunta são analisadas as respostas às seguintes perguntas do questionário: "Antes de entrar no curso de BSI você procurou se informar sobre o perfil do egresso? Considere egresso o aluno formado", "Onde você buscou informações sobre o perfil do egresso dos cursos de BSI?" e "Antes de entrar no curso de BSI você teve contato com a grade curricular?". Estas perguntas possibilitam identificar possíveis formas de construção da visão quanto ao foco do curso detectando as principais fontes de informação utilizadas pelos possíveis estudantes e o quanto de informação foi consultada. É considerada pouca informação quando o estudante acessa no máximo 2 fontes diferentes de informação, e muita informação configura um acesso a mais de 3 fontes diferentes.

\section{ANTES DE ENTRAR NO CURSO VOCÊ PROCUROU INFORMAÇÕES SOBRE O PERFIL DO EGRESSO DO CURSO?}

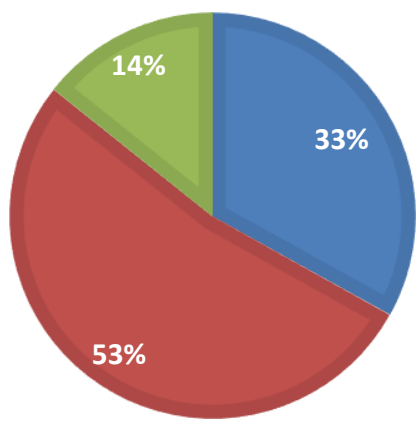

Procurei muita informação

Procurei um pouco de informação

Não procurei informação alguma

Figura 3: Respostas à pergunta "Antes de entrar no curso você procurou informações sobre o perfil do egresso do curso?"

A Figura 3 mostra que a minoria de apenas 14\% - 19 respostas, afirmam não ter procurado informação. Porém, se contrastarmos as respostas mostradas nas Figuras $1 \mathrm{e}$ 2, em que a segunda maioria dos estudantes tinha a percepção antes de ingressar ao curso de que este tratava-se apenas de Programação, há uma necessidade de avaliarmos as fontes nas quais esses estudantes estão buscando informações sobre o curso, para 
identificar se há alguma falha nessa comunicação. Para isto, são analisadas na Figura 4 as respostas à pergunta "Onde você buscou informações sobre o perfil do egresso dos cursos de SI?".

Esta pergunta no questionário possibilitava escolher múltiplas respostas pois raramente quando uma pessoa quer se informar sobre um curso, utiliza uma única fonte. O gráfico na Figura 4 mostra que a principal fonte de busca de informações quanto aos cursos de BSI ocorrem no site da própria universidade em que o estudante pretende estudar (87 respostas - 65\% do total). A segunda fonte mais buscada são conversas informais com profissionais de computação (71 respostas - $53.3 \%$ do total) e a terceira maior fonte de informações são conversas informais com estudantes do curso (com 59 respostas $-44.3 \%)$.

Pode-se interpretar estes resultados de diversas perspectivas. A primeira é que talvez os sites das universidades não estejam sendo totalmente claros quanto ao perfil do egresso. Entretanto, não se pode descartar que os estudantes podem ter acesso à informação e não interpretá-la da maneira correta ou não consumi-la de forma consistente e assim obtém interpretações "convenientes" à sua vontade, por exemplo, entender que o curso tem o foco na programação. Por fim, percepções equivocadas da área podem persistir e se propagar através dos atuais profissionais e estudantes, fontes relevantes de informação, segundo os participantes da pesquisa.

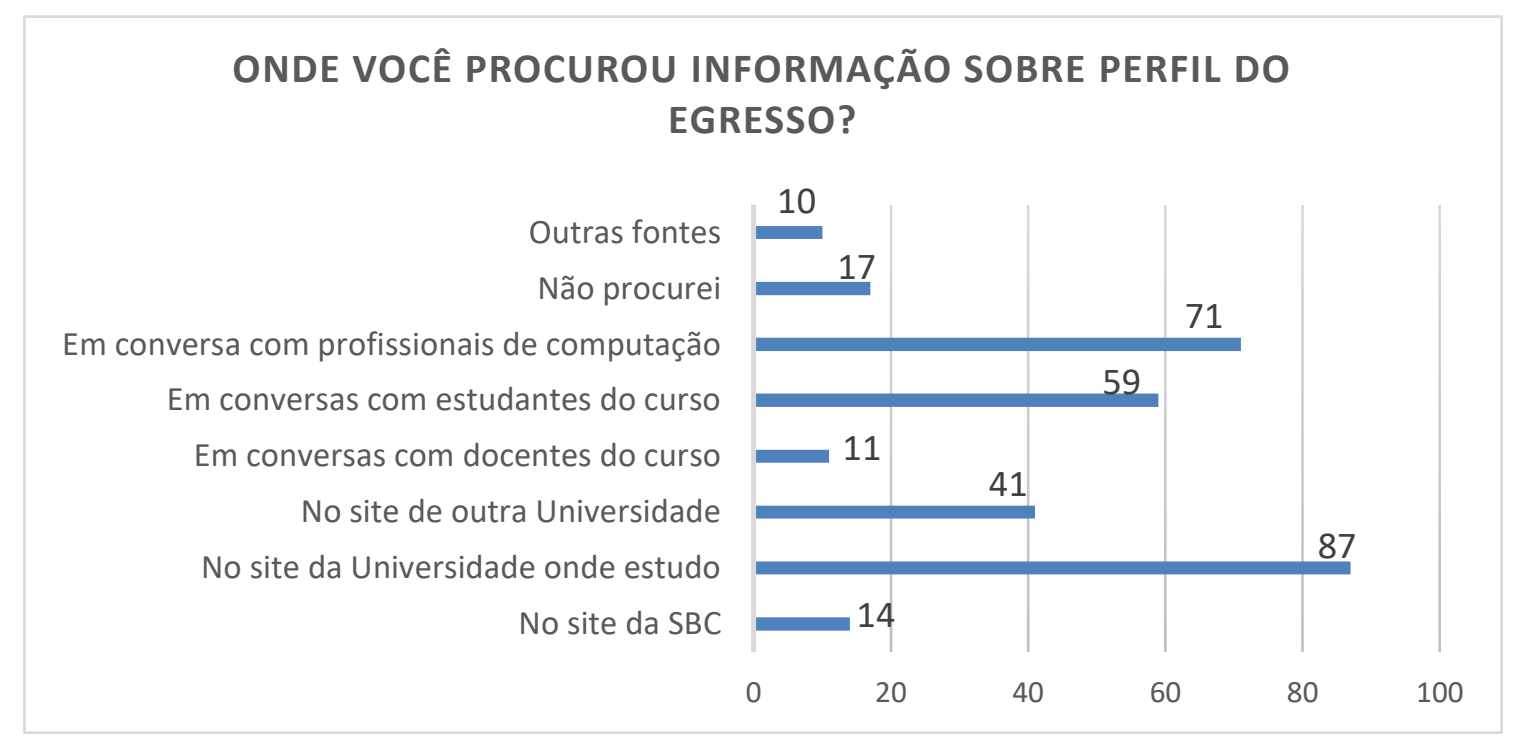

Figura 4: Respostas à "Onde você buscou informações sobre o perfil do egresso?"

Como uma das informações mais completas e claras quanto ao que se pode ter de um curso é a própria matriz curricular, o questionário possuía uma pergunta para detectar especificamente se a matriz curricular fez parte desta busca por informações sobre o curso. A Figura 5 mostra o gráfico correspondente às respostas. 


\section{VOCÊ TEVE CONTATO COM A GRADE CURRICULAR ANTES DE ENTRAR NO CURSO SI?}

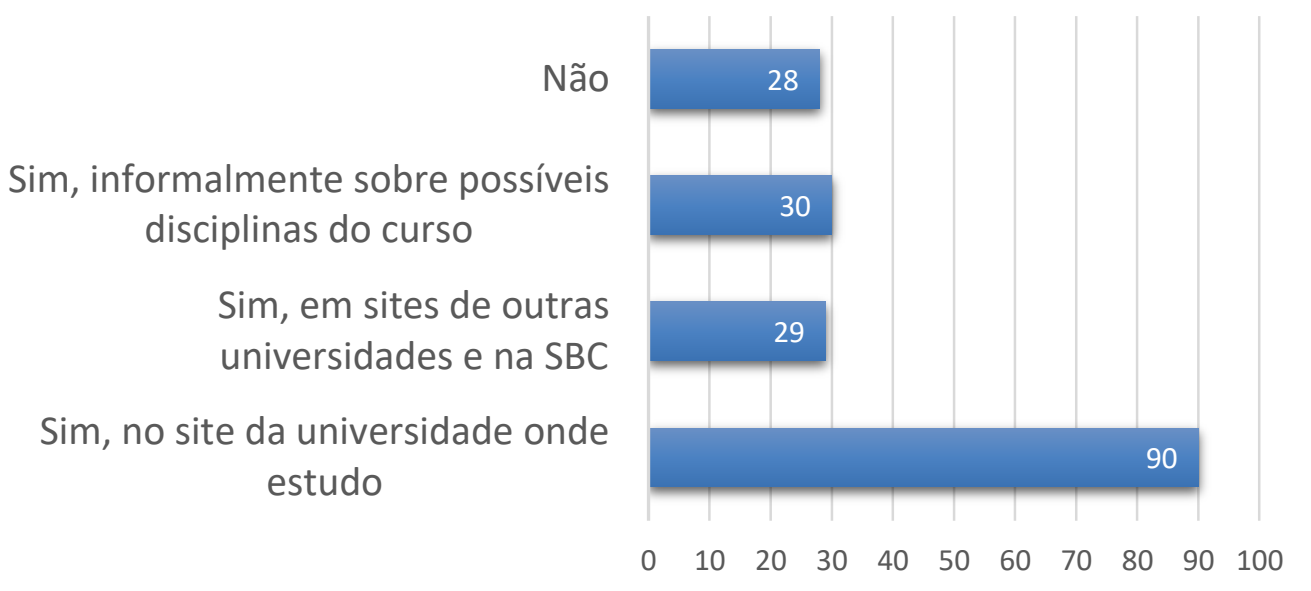

Figura 5: Respostas à "Você teve contato com a matriz curricular antes de entrar no curso de SI?"

Esta pergunta também possibilitava múltiplas respostas para cada estudante. Observando o gráfico da Figura 5 é possível perceber que os estudantes procuraram sim informação sobre a matriz curricular no site das universidades em que pretendiam estudar.

Concluindo esta análise quanto à percepção dos estudantes antes de entrar no curso e como esta percepção foi construída, é possível destacar dois aspectos positivos, que os estudantes estão buscando se informar sobre o curso em fontes formais como os sites da universidade em que pretendem cursar e que a maioria tem uma visão de que BSI tem um perfil de estudos de computação combinadas com área de negócios. Porém, também surgem contradições quando se identifica que uma boa parcela de estudantes (28\%) decidiu cursar SI apenas pelo interesse especificamente em programação. Por isso, é analisado no gráfico da Figura 6 o comportamento de busca por informações antes de entrar no curso apenas desta parcela de estudantes (37 estudantes).

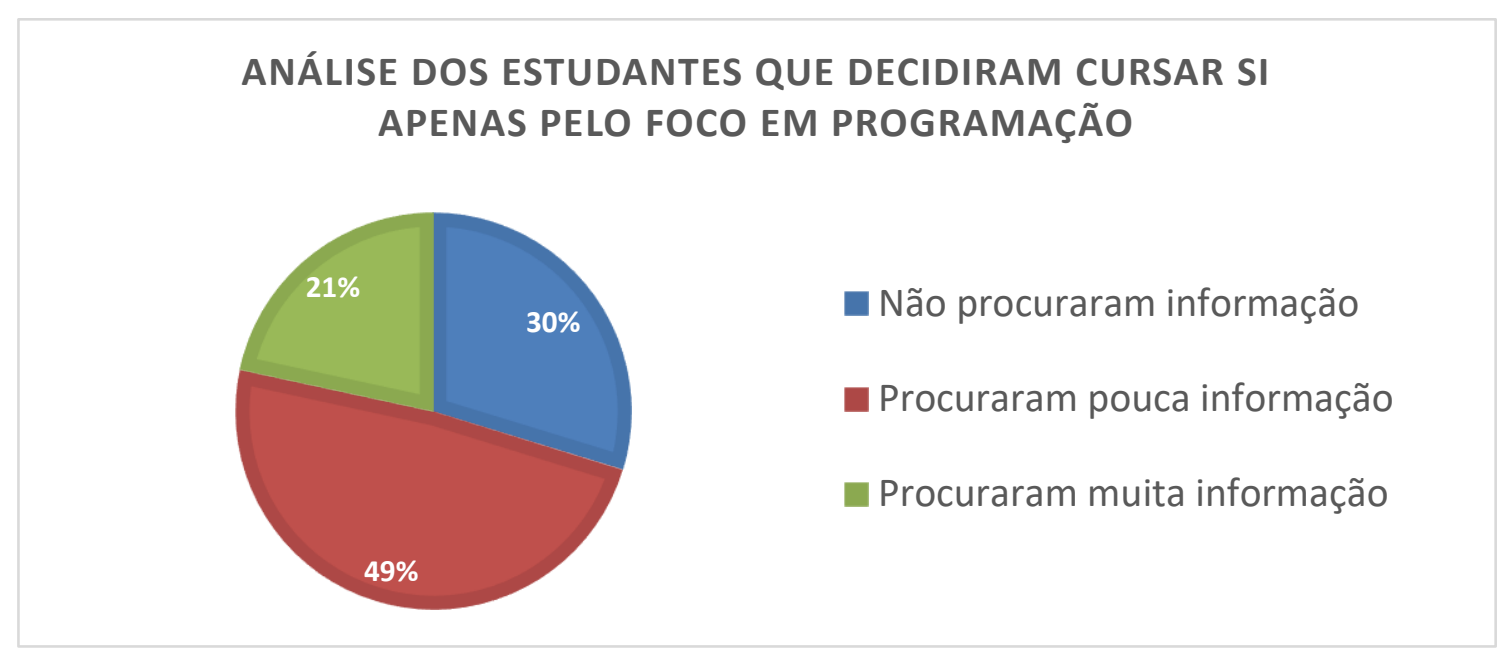

Figura 6: Análise dos 37 estudantes que possuem interesse em apenas Programação

Com esta análise observa-se que 18 estudantes buscaram pouca informação, 11 não procuraram informação e 8 buscaram muita informação antes de ingressar no curso. 
Assim, surgem algumas hipóteses: (i) mesmo conhecendo as informações do curso que indicam uma formação mais híbrida com disciplinas de computação e gestão, esses estudantes decidiram mesmo assim ingressar no curso; (ii) a parcela de estudantes que não procurou informação é expressiva chegando a $30 \%$, o que pode justificar um pouco sua percepção quanto ao foco isolado em programação.

Com essas análises seria possível responder à pergunta secundária 2: Como a percepção dos estudantes antes de ingressar no curso é construída? A fonte de informação mais buscada é o site da própria universidade em que o estudante pretende cursar BSI. Um aspecto contraditório é quanto aos estudantes que afirmam ter buscado informações, e mesmo assim acreditam que o foco do curso é em programação. Além das hipóteses já levantadas sobre uma possível falha na interpretação, seria interessante essas universidades revisarem seus sites para observar se há algum ruído na comunicação sobre a descrição do curso e do perfil do egresso.

Embora a fonte mais consultada seja o site da universidade em que os estudantes estão matriculados, é importante ressaltar que as conversas informais com profissionais e estudantes da área também são muito frequentes. Isto indica que os possíveis estudantes buscam diferentes fontes de informação. Entretanto, estas fontes parecem não conseguir esclarecer as dúvidas com relação às disciplinas do curso de BSI e o esperado perfil do egresso.

\subsection{Há crise de identidade "entre os muros" dos cursos de BSI?}

A terceira pergunta secundária é "Após o ingresso no curso de SI os estudantes percebem como uma área multifacetada ou fragmentada, gerando assim uma crise "entre os muros" da universidade? Para responder esta pergunta, analisamos respostas que tratam da percepção do estudante durante o seu curso de BSI buscando identificar se esta percepção vai ao encontro da percepção prévia à entrada no curso, ou seja, sua expectativa.

De acordo com o gráfico da Figura 7, antes do ingresso ao curso a percepção é equilibrada, com 57 respostas para a percepção fragmentada - com o foco em desenvolvimento de sistemas puramente e com 58 respostas para a percepção multifacetada - com o desenvolvimento de sistemas combinado com conhecimentos de administração e gestão. Após o ingresso no curso, a percepção multifacetada é um pouco maior (68 respostas). Assim, identifica-se que uma boa parcela de estudantes quando entram no curso, se deparam com uma realidade diferente da esperada. Entretanto, é preocupante perceber que alguns participantes não sabem responder qual é o foco do curso mesmo já estando cursando BSI. 


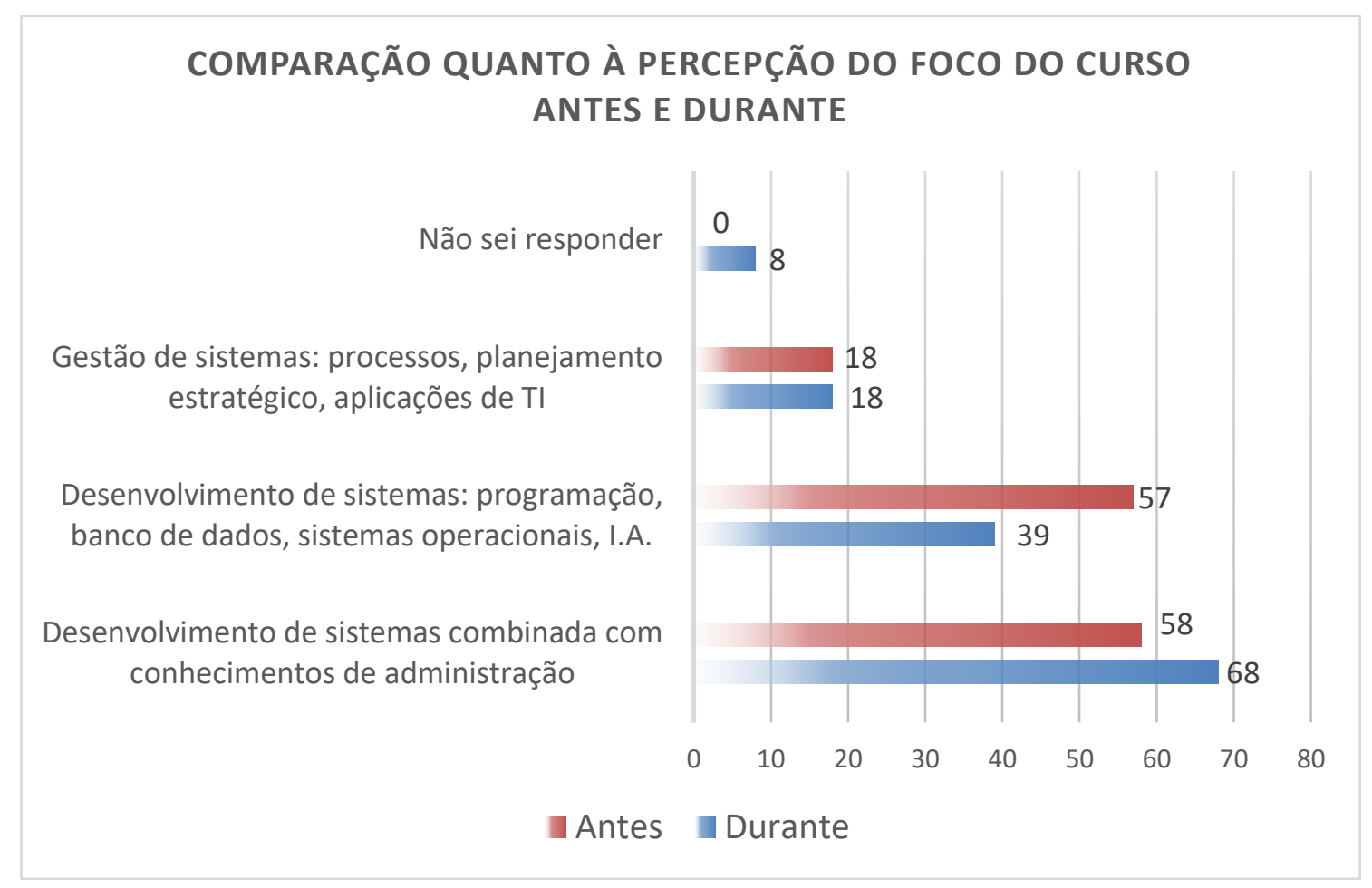

Figura 7: Comparação da percepção de foco antes e durante o curso de SI

É interessante avaliar também se a diferença percebida pelos estudantes é recebida de maneira positiva ou negativa. Pois esta diferença gera impactos, se os estudantes percebem uma diferença positiva, isto pode motivá-los a investir na carreira. Por outro lado, se eles percebem uma diferença negativa, isto pode desmotivá-los fazendo com que seu desempenho seja prejudicado ou chegando até mesmo a desistir do curso.

Para isto, as respostas à pergunta "Como você avaliam a sua expectativa sobre o curso antes de ingressar e a sua realidade atual dentro do curso?" podem auxiliar nesta análise, refletindo os seguintes números: 48.9\% (65 respostas) afirmam que há uma diferença entre a expectativa e a realidade quanto ao foco do curso que não agrada, $24,1 \%$ (32 respostas) afirmam que esta diferença agrada e 27,1\% (36 respostas) afirmam que a realidade do foco do curso está próxima à expectativa antes do curso.

Mais uma vez, é possível identificar um dos possíveis fatores de desmotivação dos estudantes ao longo do curso, pois a maioria diz que não agrada a diferença entre sua expectativa e a realidade que vive no curso.

Para caracterizar melhor a parcela de estudantes que respondeu que a diferença não agrada, foram combinadas em um único gráfico (Figura 8) as respostas às perguntas "Antes de entrar no curso de BSI qual era sua expectativa quanto ao foco do curso?" e "Considerando sua experiência no curso, qual a sua percepção quanto ao foco do seu curso?" com a pergunta "Como você avalia a sua expectativa sobre o curso antes de ingressar e a sua realidade atual dentro do curso?". Esta combinação permite detalhar qual a percepção anterior ao curso e durante o curso e identificar a qualificação dos estudantes quanto a esta diferença. 


\section{OPINIÃO DOS ESTUDANTES QUANTO À DIFERENÇA DE EXPECTATIVA E REALIDADE DO FOCO DO CURSO DE SI}

$\begin{aligned} & \text { Des. Sistemas (antes) e Des. Sistemas e Adm } \\ & \text { (durante) }\end{aligned}$
Des. Sistemas e Adm (antes) e Des. Sistemas
(durante)
Des. Sistemas (antes e durante)

Des. Sistemas e Adm (antes e durante)

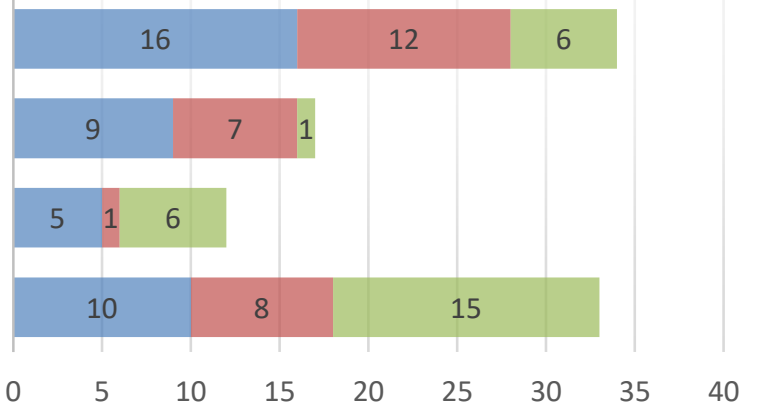

• diferença não agrada $\quad$ diferença agrada não há diferença

Figura 8: Opinião dos estudantes quanto à diferença de expectativa e realidade do foco do curso de SI

Como mostra o gráfico da Figura 8, a maioria dos estudantes (16) que tinham a expectativa de um curso puramente de desenvolvimento de sistemas e, durante o curso, percebem uma combinação entre desenvolvimento e gestão, não gostam (não agrada) da diferença percebida. Este é um dado importante para explicar a crise e direcionar ações de divulgação mais esclarecedora sobre o curso. Esta percepção inicial de que o curso de BSI tem foco em desenvolvimento de sistemas pode atrair estudantes interessados em trabalhar com computação, porém, pode também desestimulá-los ao perceber que o aprofundamento será diferente por haver também um enfoque no contexto desses sistemas nas organizações e sociedade exigindo uma formação mais híbrida com competências não apenas técnicas.

Outro fato interessante de destacar é que também há uma certa frustração entre os estudantes que inicialmente tinha uma expectativa "correta" por esperar um curso híbrido, mas durante o curso percebê-lo com um enfoque maior em desenvolvimento de sistemas. Neste caso seria necessário avaliar se não há uma supervalorização das disciplinas de desenvolvimento por parte dos docentes dos cursos, ou então, se não caracteriza uma maior dificuldade dos estudantes nessas disciplinas, fazendo com que percebam um "enfoque" inadequado da profundidade dessas disciplinas.

É curioso notar que muitos estudantes que disseram ter a mesma visão antes e depois do curso sobre o foco do mesmo responderam que a diferença agrada, onde de fato não deveria haver diferença declarada. O contrário também ocorreu, em que 6 estudantes afirmam ter expectativa e realidades diferentes, mas quando são questionados se a diferença agrada, responderam que não há diferença. Este resultado parece indicar uma grande dificuldade dos estudantes para interpretar a relação entre suas expectativas e suas realidades no curso.

No questionário, havia uma pergunta que solicitava ao estudante justificar sua resposta quanto à pergunta "Como você avalia sua expectativa sobre o curso antes de ingressar e a sua realidade atual dentro do curso?". Esta pergunta era obrigatória de texto livre, apenas 5 respostas foram inutilizadas por preencher o espaço com letras e pontos. Das 128 justificativas, muitas se resumem a dizer que o estudante achava que o curso ou deveria ser mais focado à programação ou mais focado à parte de gestão, ou ainda revelam peculiaridades específicas da universidade onde cursam, por exemplo, o 
turno. Porém destacamos algumas justificativas que podem de fato mostrar o que está e o que não está agradando no curso, e talvez caracterizar a verdadeira "crise" que ocorre dentro do curso. As justificativas numeradas de 1 a 4 têm em comum apontamentos positivos quanto ao curso:

1- "Esperava um curso que me desse autonomia, e encontrei."

2- "Sempre gostei da área da computação e já trabalhava como desenvolvedor web. Também sempre gostei de estudar sobre assuntos na área de administração. Esse curso possibilitou uma visão holística dessas duas áreas e, inclusive, permitiu me aprofundar em alguns tópicos especificos através da possibilidade de escolha de cursar "trilhas" em assuntos específicos."

2- "Eu acabei entrando no curso de BSI por não ter conseguido entrar em ciência da computação, não gostar de engenharia e não saber diferenciar muito bem o curso de ciência da computação do bacharelado em sistemas de informação. Mas, em pouco tempo e com uma boa pesquisa sobre, percebi que eu me identifico muito mais com o curso. Além disso, a abrangência, principalmente sobre os aspectos de gestão, ainda mantendo como ponto nevrálgico a formação técnica em programação, fez com que eu me apaixonasse pela área e divulgasse o curso entre meus amigos."

3- "Eu esperava um curso totalmente voltado para desenvolvimento de sistemas da informação. O enfoque em administração foi uma surpresa agradável, pois pensei em cursar Administração também."

4- "bem, eu entrei com preconceito no curso (acho que preferia ser chamado de um engenheiro de computação fracassado do que um bacharel em SI de sucesso); mas acabei gostando mais do curso agora do que eu gostava da engenharia de computação; as matérias de 'humanas' que tive (sociologia, teoria da administração, teorias organizacionais) me faziam falta e eu nem percebia isso."

As justificativas 5 à 7 têm em comum apontamentos quanto à didática dos professores e à sua desatualização frente ao que eles acreditam ser importante ser ensinado no curso:

5- "Professores desatualizados e fora de contexto do mercado/área"

6- "O curso é bem introdutório em todas as disciplinas da área. Talvez seja um problema comum à área de TI, onde a forma que os cursos de graduação são aplicados não se adeque ao que a área necessita. Talvez devêssemos ter um periodo introdutório menor e em seguida ficaria a cargo dos alunos se especializar em um dos vários setores da área. Em geral, minha opinião quanto ao curso é positiva, mas muitas pessoas reclamam frequentemente. O meu problema está mais no aprofundamento do conteúdo e em como as aulas são aplicadas, mas neste último caso entraríamos na didática dos professores onde não tivemos muitas experiências positivas."

7- "Os professores do curso não são atualizados com a realidade do mercado de trabalho, principalmente quando se trata de programação. Não possuem a didática necessária para ensinar alunos de diferentes perfis e muitas vezes o aluno precisa aprender sozinho para poder adquirir o conhecimento necessário."

8- "Não se adapta, pois, a universidade parte do preceito que já sabemos programar ou temos algum conhecimento na area de TI, o que muitas vezes não ocorre, dificultando ainda mais o aprendizado do novo aluno." 
As justificativas 9 a 14 têm em comum apontamentos quanto ao desalinhamento com a prática e o mercado de trabalho:

9- "No curso de BSI da <nome_da_universidade_omitido>, sinto uma falta de alinhamento com o mercado de trabalho atual. Em muitas disciplinas, nós estudantes ficamos presos a livros da bibliografia sem conhecer a aplicação prática dos assuntos estudados."

10- "Estou trabalhando com Gestão de TI há cerca de dois anos e infelizmente não consigo aplicar o conteúdo que aprendi/aprendo no curso no meu trabalho. Ocorre o contrário, o meu trabalho me ensinou mais sobre gestão do que a graduação."

11- "O curso é muito desatualizado, existem muitas matérias que não irão ajudar na carreira profissional dos alunos e muitas tecnologias novas que são tendências não são apresentadas no curso."

12- "Gostaria que as disciplinas de gestão tivessem um lado um pouco mais prático.”

13- "Curso com mais carga teórica do que prática, focado em programação."

14- "O curso deveria ser mais focado no mercado de trabalho."

As justificativas 15 a 18 que mencionam aspectos relacionados à pesquisa:

15- "Tinha perspectiva de que ao cursar BSI na <nome_universidade_omitido > teria mais acesso a novas tecnologias e conhecimentos inovadores. Mas o que vejo são apenas matérias e tecnologias ultrapassados. Professores que insistem em passar conteúdos antigos e muitas vezes nem são usados no mercado de trabalho. Sem falar que a maioria do que é ensinado nem se usa no mercado de trabalho e sim para formar pesquisadores, acho que deveria ter uma forma onde o aluno que quer ser pesquisador possa se adequar mas sem obrigar os alunos que querem apenas se adequar ao mercado de trabalho."

16- "Minha única reclamação é quanto a alguns docentes do curso que pensam que a maior parte da turma deseja seguir o ramo acadêmico, porém a maior parte deseja seguir para empresas."

17- "Acreditava que o curso me traria um maior aprofundamento nos conhecimentos sobre gestão de negócios, de sistemas, de empresas e afins. Além de dar uma base melhor em aplicações de mercado. Gostei bastante do enfoque na pesquisa, que acreditei que não haveria."

18- "Muito mais enfoque em pesquisa do que qualquer outra coisa".

É interessante notar que embora alguns estudantes apontem a pesquisa em SI como algo bom e diferencial nos cursos de BSI, outros percebem esta característica como algo ruim e fora da realidade de quem quer atuar no mercado. Esta relação com a área de pesquisa também pode ser analisada por meio da pergunta "Na sua opinião, qual a diferença do curso de SI para os cursos Ciência da Computação e Engenharia de Computação?” cujos percentuais estão no gráfico da Figura 9. 


\section{QUAL A DIFERENÇA ENTRE OS CURSOS SI E ENGENHARIA DE COMPUTAÇÃO E CIÊNCIA DA COMPUTAÇÃO?}

BSI é um curso para quem não tem interesse em programar mas quer trabalhar com a área de TI

- BSI tem um enfoque em disciplinas de computação, porém com menos profundidade do que os outros cursos

- BSI tem um enfoque mais interdisciplinar com disciplinas de computação e de gestão, e os outros cursos só têm enfoque em disciplinas de computação

BSI tem um enfoque para área de mercado e os outros para área de pesquisa

Não sei responder

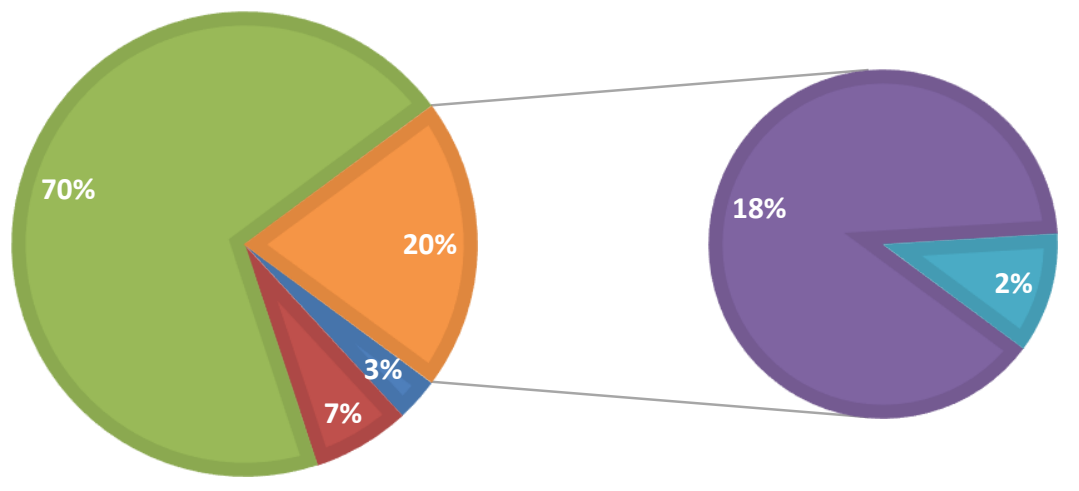

Figura 9: Percentuais quanto à diferença entre os cursos SI, Engenharia de Computação e Ciência da Computação.

Como pode ser visto a grande maioria de $70 \%$ (93 respostas) considera que a diferença entre SI e Engenharia de Computação e Ciência da Computação é justamente a interdisciplinaridade entre disciplinas de computação e gestão. Porém, destaca-se uma segunda maioria (20\% de respostas indesejadas) que mostra um aspecto interessante a ser analisado: 18\% (24 respostas) considera que "BSI tem um enfoque para área de mercado e os outros para a área de pesquisa" e $2 \%$ não sabe responder qual a diferença entre esses cursos. almejadas pelas associações e instituições. Considera-se como respostas indesejadas pois, embora sendo opções de resposta, não são opções esperadas pelas grandes instituições. Nos documentos oficiais todos os cursos devem preparar o profissional para atuar no mercado e/ou na pesquisa, conforme suas habilidades e preferências.

Quanto aos planos de carreira, foi comparada a mudança de percepção futura antes de ingressar no curso e durante o curso através do gráfico na Figura 10. Esta comparação ocorre através das respostas às perguntas "Antes de entrar no curso de BSI com o que você planejava trabalhar após formado(a)?" e "Quais os seus planos atuais de carreira para após terminar o curso?”.

Observando os números, percebe-se que antes de entrar no curso a grande expectativa futura é trabalhar com programação (37 respostas - 27,8\%), a segunda seria trabalhar como gestor de sistemas de grandes empresas (31 respostas - 23,3\%). Durante o curso o que se destaca é justamente a diminuição de respostas para trabalhar puramente com programação (26 respostas - 19,5\%). Este resultado é interessante pois 
indica que para uma pequena parcela dos estudantes, a experiência nos cursos pode estar proporcionando uma visão mais abrangente sobre as possibilidades de atuação profissional.

Houve uma falha no instrumento de coleta que não permite a comparação de intenções de investir em carreira acadêmica antes de entrar no curso. Assim, percebemos apenas a percepção futura, durante o curso de 13 estudantes $(9,8 \%)$ de respostas que planejam seguir carreira acadêmica, porém, não podemos afirmar se antes eles também o tinham.

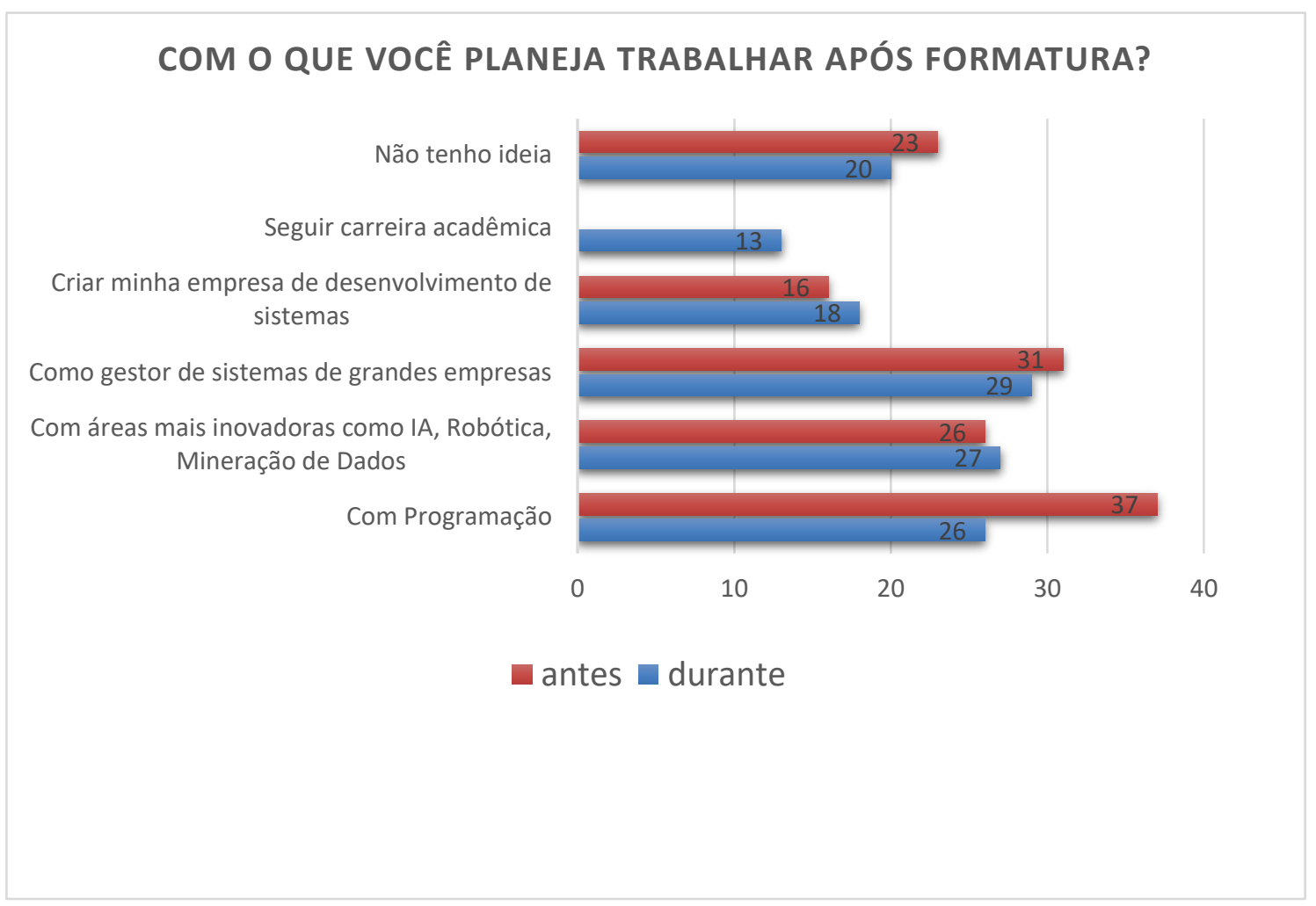

Figura 10: Comparação de percepção quanto aos planos de carreira antes e durante o curso.

Com essas análises seria possível responder à terceira pergunta secundária: “Após o ingresso no curso de SI os estudantes percebem como uma área multifacetada ou fragmentada, gerando assim uma crise "entre os muros" da universidade? Através dos gráficos analisados conclui-se que há uma "crise" dentro dos cursos, porém, uma crise diferente da que a área estava tradicionalmente acostumada a enfrentar nos cursos de SI. Analisando as respostas verifica-se que os estudantes dentro do curso passam a perceber a área como multifacetada, o que de fato espera-se que seja, porém, a uma parcela de estudantes não agrada nem a quem já esperava por isso antes do curso e nem por quem não esperava. Parece que a crise acontece na "forma" com que as multifaces são apresentadas no curso, através de falhas em vários pontos na tentativa de se desenvolver uma área com visões diversificadas.

\section{O que os comentários livres dos estudantes têm a ensinar?}

Para poder capturar algum outro aspecto que não foi tratado durante as perguntas do questionário, foi formulada uma pergunta aberta não obrigatória para aqueles que quisessem expressar alguma consideração geral sobre o curso: "Para finalizar, você teria 
alguma consideração a fazer sobre o seu curso, que não foi questionada aqui, mas, que você sempre teve vontade de expressar apesar de nunca ter tido oportunidade?". Como a resposta não era obrigatória, apenas 51 estudantes voluntariamente expressaram suas opiniões sobre variados aspectos. No gráfico da Figura 11, através da leitura dos comentários, destacam-se algumas possíveis categorias dos comentários: professores, matriz curricular, mercado de trabalho e outros que abrangem situações de turno, provas e infraestrutura da universidade.

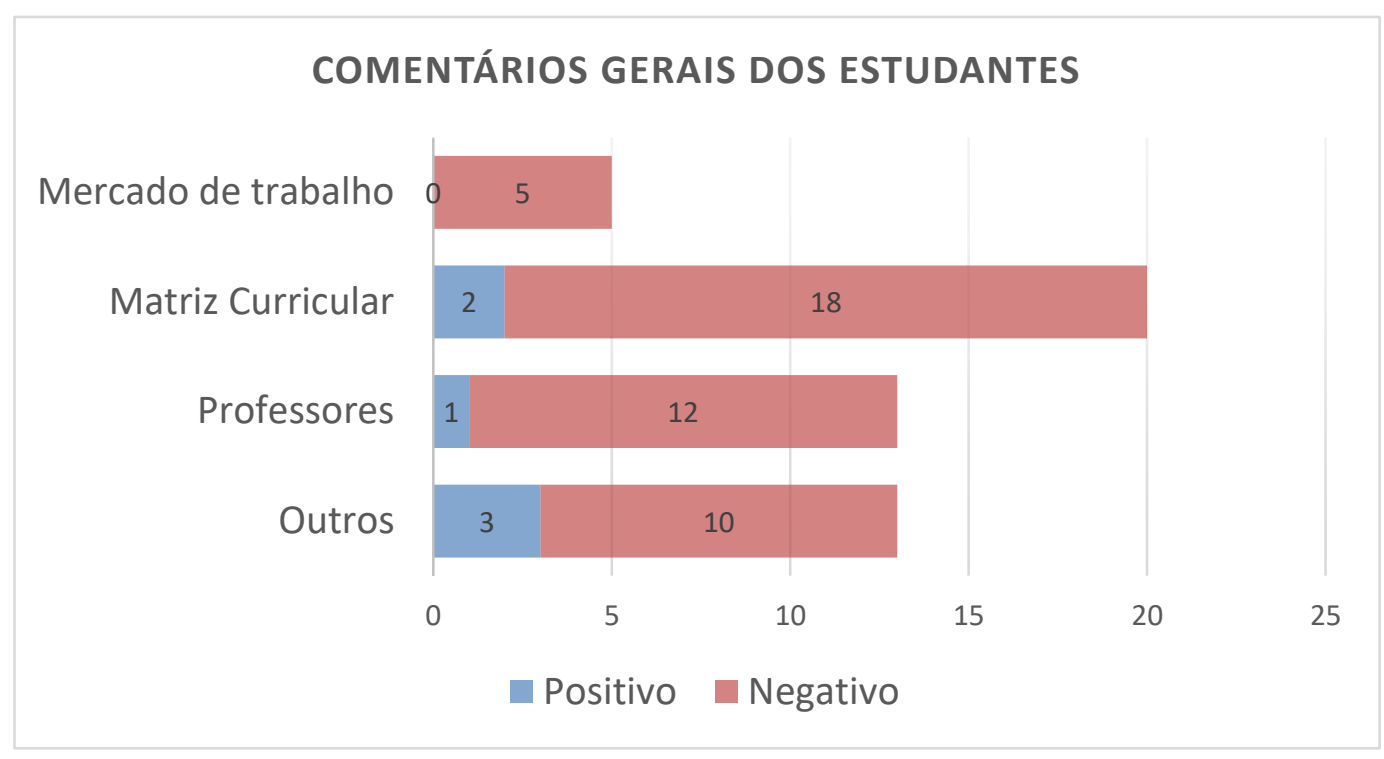

Figura 11: Análise dos comentários gerais dos estudantes.

No geral, a maioria dos comentários é com relação a pontos negativos principalmente com relação à matriz curricular, não exclusivamente, pois alguns comentários misturam assuntos como matriz, professor e infraestrutura e tempo de conclusão do curso. Abaixo estão expostos alguns comentários que são mais enfáticos em alguns desses aspectos:

"A área de sistemas evolui muito rápido e os currículos das faculdades estão sempre muito atrasados, quando uma disciplina entra na grade curricular ela já está ultrapassada."

"Acredito que o currículo da <nome_universidade_omitido> precisa ser mais atual, além disso, deveria ser atualizada também as tecnologias ensinadas para os alunos durante o curso. A área mobile por exemplo, tem crescido cada vez mais e a $<$ nome_universidade_omitido $>$ não oferece nenhuma disciplina sobre o assunto"

"A área é incrível e tenho certeza que é com o que quero continuar trabalhando. $O$ curso de Sistemas de informação é justamente o que eu queria para a minha formação. Infelizmente, alguns professores da minha instituição de ensino estão muito aquém do esperado e desmotivam o aluno, colaborando com a evasão. Se soubesse desse problema, teria buscado por outra universidade quando decidi pelo curso de sistemas de informação."

"Por que alguns professores nunca estiveram no mercado de trabalho? Por que sua formação se dá exclusivamente dentro da escola? Não seria interessante ter contato com o mercado nem que por um curto período?"

"Gostaria de ter aula com professores de SI, não de Ciência da Computação ou engenheiros" 
"Um profissional na área de computação não precisa ser apaixonado por programação. A computação e o pensamento computacional, principalmente quando falamos de sistemas de informação, podem ser aplicados em outros universos. Considero importante deixar isso claro aos estudantes do curso, pois abrirá os horizontes em relação ao mercado de trabalho, e servirá como incentivo para os "menos computeiros".

"Entrei no curso como sendo uma segunda opção, mas ele acabou se tornando a opção certa, já que não me vejo fazendo outra coisa hoje. As pessoas precisam conhecer melhor sobre ele para empreender em que não é só "coisa de nerd" e que é sim uma opção de carreira muito boa e que pode trazer muito sucesso na vida profissional."

A análise das respostas à questão optativa indica a necessidade de alguns estudantes expressarem, principalmente, suas decepções com relação aos cursos. Entretanto, não é possível afirmar categoricamente as razões de tais decepções. Percebese que muitos fatores, inclusive externos ao contexto da área, por exemplo, a divulgação das possibilidades de cursos superiores que podem ser cursados, influencia a postura dos estudantes diante da experiência vivida nos cursos.

Com esta pequena amostra, conclui-se que não se deve encarar os estudantes como personagens totalmente passivos em um curso, os quais muitas vezes apresentam dificuldades que não passam simplesmente por base matemática fraca ou metodologia de ensino ultrapassada, mas passa por uma visão diferente, até mesmo por uma frustração com relação à expectativa e motivação inicial de cursar o curso.

\section{Considerações finais}

O objetivo deste trabalho foi identificar se a histórica crise de identidade dos cursos de SI ocorre "além-muros" dos cursos através da percepção dos estudantes antes seu ingresso no curso, ou se ocorre somente "entre os muros" dos cursos através da percepção dos estudantes após seu ingresso. Com a participação de 133 estudantes de 2 universidades públicas e 2 privadas da região sul do Brasil foi possível detectar que a crise pode ocorrer sim "além-muros", visto que uma boa parcela de estudantes cria uma falsa expectativa quanto ao curso esperando seu enfoque exclusivamente em programação. Observa-se também que os estudantes alegam procurar por informações sobre o curso como grade curricular e perfil do egresso nos websites das universidades em que pretendem estudar, deixando a dúvida quanto ao peso dessas informações para formar percepções tão adversas. Embora haja a consulta aos materiais oficiais, como os currículos de referência da SBC e os documentos das universidades, há também, com frequência semelhante, conversas informais com os atuais profissionais e estudantes dos cursos de SI. Diante disto, considera-se necessário e relevante investigar qual é realmente a fonte de informação que está gerando interpretações equivocadas e/ou enviesadas sobre os cursos e as possibilidades de atuação profissional que eles oferecem.

Também se verificou que a crise de identidade entre os muros do curso talvez não ocorra mais pelo não entendimento de que o curso é multifacetado, mas pela forma com que esta multidisciplinaridade ocorre. Um aspecto positivo pode ser caracterizado através de uma "transição" de crise, na qual, talvez os cursos já consigam se definir melhor. Porém, a forma como essas definições são implementadas talvez configure a nova "crise" dos cursos de SI.

Como trabalhos futuros, objetiva-se expandir a pesquisa para outras regiões do país e avaliar se o aspecto geográfico é uma variável relevante na análise da crise de 
identidade. Esta expansão da pesquisa permitirá reduzir as limitações do estudo aqui apresentado, como a baixa representatividade das respostas com relação ao número total de estudantes no país e a impossibilidade de generalização das conclusões. Apesar destas limitações, é importante salientar que a abordagem aqui exposta por meio da descrição das percepções de uma parcela de estudantes de SI já pode indicar novos insights sobre o problema, como uma nova crise.

\section{Referências}

ACM (2010), The Curriculum Guidelines for Undergraduate Degree Programs in Information Systems, Association for Computing Machinery and Association for Information Systems. https://www.acm.org/education/curricula-recommendations

Amorim, G. (2015) "O Mercado de Profissionais de Tecnologia da Informação e Comunicação no Brasil: uma análise do período de 2006 a 2013". http://www.brasscom.org.br/brasscom/Portugues/download.php?cod=1775.

Araujo, R., Ralha, C., Graeml, A. e Cidral, A. (2015). A Comunidade de Pesquisa em Sistemas de Informação no Brasil na perspectiva do Simpósio Brasileiro de Sistemas de Informação. iSys-Revista Brasileira de Sistemas de Informação, 8(1), 5-17. http://seer.unirio.br/index.php/isys/article/view/5136 [GS Search]

Benbasat, I. and Zmud, R. W. (1999). Empirical research in information systems: the practice of relevance. MIS Q. 23, 1 (March 1999), 3-16. doi: 10.2307/249403. [GS Search]

Cavalcante, F. P.L. e Embiruçu, M. S. (2013) Aprendizado com base em problemas: Como entusiasmar os alunos e reduzir a evasão nos cursos de graduação em engenharia; XLI Congresso Brasileiro de Ensino em Engenharia, v. 2013. http://www.fadep.br/engenharia-eletrica/congresso/pdf/116536 1.pdf [GS Search]

Dahlberg, T., Barnes, T., Rorrer, A., Powell, E. and Cairco, L. (2008). Improving retention and graduate recruitment through immersive research experiences for undergraduates. In Proceedings of the 39th SIGCSE Technical Symposium on Computer Science Education, SIGCSE '08, pages 466-470, New York, NY, USA. ACM. doi: 10.1145/1352322.1352293 [GS Search]

Davenport, T.H. Storming the Tower. (1997) CIO Magazine https://books.google.com.br/books?id=gAYAAAAAMBAJ.

Digiampietri, L. A., de Souza Lauretto, M. e Nakano, F. (2016). Estratégia de Análise Quantitativa para Revisão de Pré-requisitos em uma Matriz Curricular do Curso de Bacharelado em Sistemas de Informação. iSys-Revista Brasileira de Sistemas de Informação, 9(2). http://seer.unirio.br/index.php/isys/article/view/5430 [GS Search]

Faquin, G. S. e Araújo, M. A. P. (2017). Uma Avaliação Preliminar da Relação Entre Desempenho Acadêmico e Tipo Psicológico em Acadêmicos de Sistemas de Informação. iSys-Revista Brasileira de Sistemas de Informação, 10(2), 138-152. http://seer.unirio.br/index.php/isys/article/view/6151 [GS Search]

Helfert, M. and Duncan, H. (2007). Evaluating information systems and business informatics curriculum. In Proceedings of the 2007 International Conference on 
Computer Systems and Technologies, CompSysTech '07, pages 73:1- 73:5, New York, NY, USA. ACM. doi: 10.1145/1330598.1330676 [GS Search]

Macedo, S. M. S., Barbosa, R. R. (2013) Information management, information technology and behavior and values relation to information in higher education institutions of Belo Horizonte. Brazilian Journal of Information Science, v. 7, n. Esp., 2013. http://search.proquest.com/openview/2031e1303f929c667f6b805e5bfbcff0/1?pqorigsite $=$ gscholar\&cbl $=2037570$ [GS Search $]$

MEC (2012). Diretrizes Curriculares Nacionais para os cursos de graduação em Computação, Ministério da Educação. http://portal.mec.gov.br/mais-educacao/323secretarias-112877938/orgaos-vinculados-82187207/18689-computacao.

Medeiros, S. M. O. e Melo, J.C.B. (2011) Metodologias para o Ensino de Ciência da Computação na Educação Básica. XI Jornada de Ensino, Pesquisa e Extensão $\begin{array}{llll}\text { JEPEX } & 2011 & - & \text { UFRPE. }\end{array}$ http://www.eventosufrpe.com.br/2011/cd/resumos/R0325-2.pdf [GS Search]

Oliveira Nunes, A., Veloso da Silva, T., Moura Mota, J., Lima Ferrer de Almeida, A. and Bandeira Andriola, W. (2015). Developing an instrument for assessment of academic management in engineering courses. Latin America Transactions, IEEE Revista IEEE America Latina, 13(1):264-271. doi: 10.1109/TLA.2015.7040657 [GS $\underline{\text { Search }]}$

Rodrigues, F. J. e Ludmer, G. (2005). Sistema de Informação: que ciência é essa?. JISTEM - Journal of Information Systems and Technology Management, 2(2), 151166. http://www.redalyc.org/html/2032/203219587004/ [GS Search]

Thompson, L. D., Eney, C., Davis, R. e Grady, T. (2014). Recruit and retain women in undergraduate computing: Success stories using research-based practices. In Proceedings of the 45th ACM Technical Symposium on Computer Science Education, SIGCSE '14, pages 541-542, New York, NY, USA. ACM. doi: $\underline{10.1145 / 2538862.2538865}$ [GS Search] 